\title{
An equation for the replacement value of agroforestry
}

\author{
W. G. MOSELEY \\ School of Natural Resources \& Environment, University of Michigan, Ann Arbor, MI 48109, \\ USA
}

Key words: agroforestry, economics, fallow, replacement value of intercropping (RVI), R factor, sustainability

\begin{abstract}
This article examines some of the existing analytical tools which quantify both the ecological and economic aspects of intercropping decisions. The characteristics of tree crops are evaluated to determine how a specific tool, the replacement value of intercropping (RVI), could be modified to better interpret agroforestry improvements to bush fallow farming systems. The modified equation captures some of the potential production improvements associated with agroforestry by accounting for the fraction of time that a field is actually in production over the long run. The result is an improved estimate of the average annual difference between a tree/crop polyculture and a monoculture system which employs fallows.
\end{abstract}

\section{Introduction}

This article examines some of the existing analytical tools which address both the ecological and economic considerations involved in intercropping decision. The characteristics of tree crops are then evaluated to determine how a specific analytical tool, the replacement value of intercropping (RVI) [Vandermeer, 1989, p. 25], could be modified to better interpret agroforestry improvements to bush fallow farming systems. The end result is a modified RVI, or replacement value of agroforestry equation, which is better able to predict the economic attractiveness of agroforestry systems to bush fallow farmers.

\section{Analytical tools}

The most basic analytical tool that scientists generally employ to evaluate polycultures is the land equivalent ratio (LER) [Mean and Willey, 1980]. The LER is calculated as:

$$
L E R=\left(\mathrm{P}_{1} / M_{1}\right)+\left(P_{2} / M_{2}\right)
$$

where $P_{1}$ and $P_{2}$ are the yields of two different crops in polyculture and $M_{1}$ and $M_{2}$ are the yields of these crops in monoculture. The resulting figure is the number of units of land in monoculture that it would take to produce the same quantities of crops 1 and 2 in polyculture. Therefore, any result over 1 would signify a polyculture advantage. The problem is that such a calcula- 
tion does not account for the value of the crops that are being grown. One's first reaction might be to multiply all crop quantities through by their appropriate prices to rectify this. However, one will quickly notice that the result is the same as both the numerator and denominator for any given crop are being multiplied by the same number. Greater elucidation occurs when the intercrop is compared to the most valuable of the two monocultures. Such a comparison is what a farmer would most likely do if he/she were concerned about monetary value [Vandermeer, 1989, p. 24]. The relative value total (RVT) attempts to do this and is computed as:

$$
R V T=\left(a P_{1}+b P_{2}\right) /\left(a M_{1}\right)
$$

where $P_{1}$ and $P_{2}$ are the yields of crops 1 and 2 in polyculture; $a$ and $b$ are the respective prices of these crops; and $M_{1}$ is the yield of the primary crop in monoculture. A slightly more complex, and the author's preferred measure for economic viability, is the replacement value of intercropping (RVI) which is calculated as:

$$
R V I=\left(a P_{1}+b P_{2}\right) /\left(a M_{1}-c\right)
$$

The difference between this measure and the RVT is that it takes account of the input costs $(c)$ associated with the aforementioned monoculture yield, e.g. insecticides, fertilizers, etc. The result of this equation is the factor by which the polyculture is more or less valuable than the monoculture. As an example, data from experiments by Singh et al. [1986]; with sorghum (Sorghum spp.) and Leucaena leucocephala in India will be used [cited in VanDenBeldt, 1990 , p. 170]. In intercrop experiments where Leucaena leucocephala was pollarded, the sorghum grain yield was found to be 1.5 tonnes/hectare and the Leucaena leucocephala fodder yield was 10.4 tonnes/hectare. The monoculture grain yield of sorghum was 2.8 tonnes/hectare. While no inputs were used to achieve the aforementioned monoculture result, it is important to note that other researchers have calculated the inputs needed to sustain such an output [e.g. Dancette and Poulain cited in VanDenBeldt, 1990]. The price for sorghum will be assumed to be US $\$ 500 /$ tonne and that of fodder to be US\$50/tonne. With this information one can then compute the RVI: [(US\$500/tonne) (1.5 tonnes/hectare) + (US\$50/tonne) (10.4 tonnes/hectare)]/ [(US\$500/tonne) $(2.8$ tonnes/hectare $)-$ US\$0] $=0.91$. The result of 0.91 indicates that the polyculture harvest has a value that is $91 \%$ of that produced by a sorghum monoculture. Such a result suggests that a farmer would not chose the agroforestry system over the monoculture. This result will be evaluated again once the RVI has been modified to reflect more clearly the long term benefits of tree crops. 


\section{Tree crop considerations}

Given that the benefits and particularly the life cycle of trees differ significantly from those of crops, some modifications to the RVI equation must be considered if it is to be an effective predictor of the economic viability of agroforestry systems. The conservation benefits of agroforestry have been widely discussed in the literature and include: maintenance of and/or improvements in soil fertility, lower levels of water and wind erosion, lower levels of transpiration, and the shortening of fallow periods without adverse consequences. A few concrete examples are cited below.

Soil nutrient levels have been improved by using trees in some agricultural systems. In West Africa where the Acacia albida is commonly used in parkland systems (mature trees widely dispersed in cropped fields) researchers have found $40 \%$ more organic carbon and nitrogen, $42 \%$ more exchangeable carbon and moderate increases in phosphorous and potassium in soils under Acacia albida trees as compared to soils away from the trees. It was found that green manure additions of over 100 tonnes/hectare would be necessary to provide equivalent soil improvement [Dancette and Poulain cited in VanDenBeldt, 1990, pp. 165-167]. In another example, alley cropping trials in Nigeria have shown that soil erosion can be significantly reduced. In a Leucaena leucocephala alley cropping system where alleys were spaced four metres apart, soil erosion was reduced from 14.9 tonnes/hectare/year (in the control) to 0.2 tonnes/hectare/year. The existence of trees did not affect maize (Zea mays) yields but it did reduce cowpea (Vigna spp.) yields considerably [Sanchez, 1987, p. 212].

CARE's Majjia Valley project in Niger has created great interest in the value of windbreaks which were shown to effectively protect crops from the effects of desiccation, sandblasting and burying caused by strong winds. Millet (Pennisetum spp.) fields protected by these Azadirachta indica windbreaks were shown to have significantly higher yields [VanDenBeldt 1990, pp. 174-175]. Finally, a major advantage of some agroforestry systems (e.g. alley cropping) over traditional shifting cultivation and bush fallow systems is that the "cropping and fallow phases can take place concurrently on the same land, thus allowing the farmer to crop for an extended period, without returning the land to bush fallow' [Zimmermann, 1986, p. 265].

The question is whether the previously described benefits are completely accounted for in increased polyculture yields or decreased input costs, the only potential proxies for these improvements in the RVI equation. The problem is that the RVI equation only accounts for crop yields in the present while agroforestry systems also yield significant benefits in the future. Soil improvements for example, are not generally reflected in increased yields immediately but rather in yields over time and/or shorter fallow periods. A holistic analysis must account for sustainable land use benefits. According to Anthony Young 'Sustainable land use is that which achieves production combined with conservation of the resources on which that productivity 
depends' [Young, 1989, p. 10]. While some may argue that longer run considerations may not be of concern to the average smallholder, research by the author in Mali demonstrated that farmers are aware of and concerned about the long term productivity of their soils [Moseley, 1993, pp. 33, 44]. If longer term benefits could be incorporated into the RVI equation then its ability to predict the economic attractiveness of agroforestry systems would be enhanced.

\section{The replacement value of agroforestry}

The fraction of the total land use cycle (growing years over growing years plus fallow years) devoted to cultivation for a tree/crop polyculture over the same fraction for a monoculture system would represent a sustainability adjustment that could be multiplied by the RVI for an improved result. This adjustment is similar to the $\mathrm{R}$ factor which is defined as: [(years under cultivation $) /($ years under cultivation plus fallow)] $\times 100$ [Young, 1989, p. 86]. While the adjustment does not account for increasing yields over time due to conservation benefits, it does account for the increased number of continuous cropping years that can result from agroforestry practices.

The aforementioned adjustment can be illustrated using the Singh et al. [1986], Leucaena leucocephala/sorghum example that was described earlier in this article. Since no cultivation or fallow periods were reported for this experiment, these lengths will be assumed for demonstration purposes to be 10 years for each period respectively. The resulting productive fraction would be $10 /(10+10)$ or 0.5 . This means that during the land use cycle the land is actually in production $50 \%$ of the time. It will also be assumed that a farmer, either using or not using chemical inputs might cultivate the same area in a monoculture of sorghum for 10 years and then find that it takes 20 years for the land to recover in fallow. Here the resulting productive fraction would be $10 /(10+20)$ or 0.33 . The ratio of the first over the second is $0.5 / 0.33$ or 1.52 (a result the author calls the comparative production factor) which means that the agroforestry system is in production $52 \%$ more of the time over an infinite stream of years than the monoculture system.

Taking the comparative production factor into consideration, the RVI is transformed into the replacement value of agroforestry and is defined as follows:

$$
\left\{\left[a P_{1}+b P_{2}\right]\left[G_{p} /\left(G_{p}+F_{p}\right)\right]\right\} /\left\{\left[a M_{1}-c\right]\left[G_{m} /\left(G_{m}+F_{m}\right)\right]\right\}
$$

where all the variables are the same as in the RVI equation with the addition of $G_{p}$ and $G_{m}$ representing the number of growing years for polyculture and monoculture and $F_{p}$ and $F_{m}$ representing the number of fallow years for polyculture and monoculture. Using the Singh et al. [1986], Leucaena 
leucocephala/sorghum intercrop example, one finds that when one calculates the replacement value of agroforestry, which is actually the RVI (that was previously found to be 0.91 ) multiplied by the comparative production factor (previously found to be 1.52), the result is 1.38 . This result indicates that the agroforestry system is $38 \%$ more productive than the sorghum monoculture over an infinite stream of years. Another way of saying it is that by accounting for the fraction of time that a field in actually in production over time, one can come up with a much better estimate of the average annual difference between a tree/crop polyculture and a crop monoculture in cropping systems which employ fallowing. This is very different from the one-time factor difference that is obtained when an agroforestry system is simply evaluated using the RVI equation.

The question arises whether the RVA is functional when there is no fallow period for either the mono or polycropped situation. It is in fact the case that a considerable amount of agriculture in the tropics is now more or less under continuous cultivation. The implication of this is that soil fertility has reached some low level of equilibrium, i.e. a stable system with low yields [Young, 1989 , p. 87]. If one is comparing a polyculture with a monoculture that involves no fallowing period, then the productive fraction for the monoculture simple goes to one. In other words, if $F_{m}=0$, then $G_{m} /\left(G_{m}+F_{m}\right)=1$. It could also be the case that an agroforestry situation may eliminate the need for fallow periods (resulting in a productive fraction of 1 for the polyculture) while the monoculture system still requires fallow periods. The quotient of the two, the comparative production factor, will still provide information on what fraction of time the agroforestry system is in production relative to the comparable monoculture. Of course if there is no fallow period for either the monoculture of polyculture situation, then the RVA will yield the same result as the RVI equation.

While the proposed replacement value of agroforestry equation is not free of problems, it is a better relative measure of agroforestry benefits in bush fallow farming systems than its forerunner, the replacement value of intercropping. While keeping calculation to a minimum, the replacement value of agroforestry equation attempts to capture some of the potential long term production improvements associated with agroforestry by accounting for the fraction of time that a field is actually in production over the long run. The result is a much better estimate of the average annual difference between a tree/crop polyculture and a crop monoculture in cropping systems which employ fallowing.

\section{References}

Mead R and Rilley RW (1980) The concept of a 'land equivalent ratio' and advantages in yields from intercropping. Exp Agr 16: 217-228

Moseley WG (1993) Indigenous agroecological knowledge among the Bambara of Djitoumou, 
Mali: foundation for a sustainable community. Master's thesis, University of Michigan, Ann Arbor, MI, USA

Sanchez PA (1987) Soil productivity and sustainability in agroforestry systems. In: Steppler HA and Nair PKR, eds, Agroforestry: A Decade of Development. ICRAF, Nairobi

Singh RP, VanDenBeldt RJ, Hocking D and Korwar GR (1986) Alley cropping in the semiarid regions of India. Paper Presented at a Workshop on Alley Cropping, 10-14 March, International Institute of Tropical Agriculture, Tbadan, Nigeria

VanDenBeldt RJ (1990) Agroforestry management in the semiarid tropics. In: MacDicken KG and Vergara NT, eds, Agroforestry: Classification and Management. Wiley, New York

Vandermeer J (1989) The Ecology of Intercropping. Cambridge University Press, New York

Young A (1989) Agroforestry for Soil Conservation. ICRAF, Nairobi and CAB International, Walingford, UK

Zimmermann T (1986) Agroforestry - last hope for conservation in Haiti? Agroforestry Systems 4: $255-268$ 